\title{
Does "Could" Lead to Good? Toward a Theory of Moral Insight
}

\section{Citation}

Zhang, Ting, Francesca Gino, and Joshua Margolis. "Does 'Could' Lead to Good? Toward a Theory of Moral Insight." Harvard Business School Working Paper, No. 14-118, June 2014.

\section{Permanent link}

http://nrs.harvard.edu/urn-3:HUL.InstRepos:13479243

\section{Terms of Use}

This article was downloaded from Harvard University's DASH repository, and is made available under the terms and conditions applicable to Open Access Policy Articles, as set forth at http:// nrs.harvard.edu/urn-3:HUL.InstRepos:dash.current.terms-of-use\#OAP

\section{Share Your Story}

The Harvard community has made this article openly available.

Please share how this access benefits you. Submit a story.

\section{Accessibility}


H A R VAR D

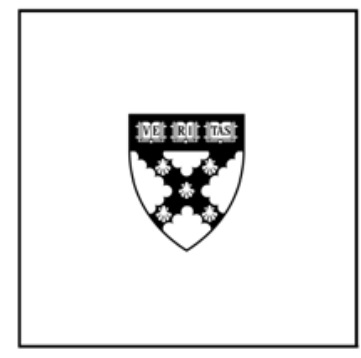

\section{Does "Could" Lead to Good? Toward a Theory of Moral Insight}

Ting Zhang

Francesca Gino

Joshua Margolis

\section{Working Paper}

14-118

June 2, 2014 
Running Head: DOES COULD LEAD TO GOOD?

\title{
Does “Could” Lead to Good?
}

\section{Toward a Theory of Moral Insight}

\author{
Ting Zhang \\ Francesca Gino \\ Joshua Margolis
}

Harvard Business School

Harvard University 


\begin{abstract}
We introduce the construct of moral insight and study how it can be elicited when people face ethical dilemmas — challenging decisions that feature tradeoffs between competing and seemingly incompatible values. Moral insight consists of discovering solutions that move beyond selecting one conflicting ethical option over another. Moral insight encompasses both a cognitive process and a discernible output: it involves the realization that an ethical dilemma might be addressed other than by conceding one set of moral imperatives to meet another, and it involves the generation of solutions that allow competing objectives to be met. Across four studies, we find that moral insight is generated when individuals are prompted to consider the question "What could I do?" in place of their intuitive approach of considering "What should I do?" Together, these studies point toward a theory of moral insight and important practical implications.
\end{abstract}

\title{
Keywords
}

Moral insight; Ethical dilemma; Could mindset; Creativity; Divergent thinking 


\section{Does Could Lead to Good? \\ Toward a Theory of Moral Insight}

Employees and managers regularly face ethical challenges that involve tradeoffs between competing moral values or principles (Toffler, 1986; Badaracco and Useem, 1993; Paine, 1997; Palmer, 2012). For instance, imagine that during a private conversation with a friend working at another company, you learn some confidential information about an impending event that will put your own company and one of its clients at great risk of considerable loss (Badaracco and Useem, 1993). This dilemma presents two possible courses of action: disclose the information to your boss, who can take action to prevent the loss, but in so doing, breach confidentiality and loyalty to a friend; or uphold your commitment to confidentiality and friendship by remaining silent, thereby risking tremendous damage to your employer and one of its clients. In this moral dilemma and in others, the competing principles are both highly valued, and choosing one value seems to necessitate forgoing the other, making the problem difficult to solve with no obvious "right" answer.

Despite the prevalence of ethical dilemmas in organizations, to date research in ethics has predominately focused on misconduct, another type of ethical challenge in which individuals understand the morally "right" path, but fail to follow their moral compass (Tenbrunsel, 1998; Schweitzer, Ordóñez, and Douma, 2004; Mead, Baumeister, Gino, Schweitzer, and Ariely, 2009; Tenbrunsel, Diekmann, Wade-Benzoni, and Bazerman, 2010; Bazerman and Gino, 2012). A growing body of research has illuminated how people approach temptations to cheat and lie (Chugh and Bazerman, 2007; Shu, Gino, and Bazerman, 2011; Moore, Detert, Trevino, Baker, and Mayer, 2012) as well as the myriad organizational sources of misconduct (Darley, 1996; 
Vaughan, 1999; Brief, Buttram, and Dukerich, 2001; Palmer, 2012), while beginning to find potential remedies (Gino and Margolis, 2011; Shu, Mazar, Gino, Ariely, and Bazerman, 2012). But when it comes to ethical dilemmas, there is a striking dearth of research on (1) how people cognitively approach organizationally relevant moral dilemmas; (2) how they resolve those dilemmas; and (3) what effective interventions might exist to enhance their capacity to find resolutions to dilemmas. Because people facing moral dilemmas often arrive at a solution or decision after weighing their options, past research has investigated how, why, and under what conditions people choose one ethical imperative over the other (Kohlberg, 1971; Gilligan, 1982; Greene, Sommerville, Nystrom, Darley, and Cohen, 2001; Greene, Morelli, Lowenberg, Nystrom, and Cohen, 2008). More recently, researchers have found that emotions influence ethical judgments and decisions, which had long been assumed in psychology to be a product of logical and deliberative reasoning (Haidt, 2001; Greene, Nystrom, Engell, Darley, and Cohen, 2004; Monin, Pizarro, and Beer, 2007; Ditto, Pizarro, and Tannenbaum, 2009; Uhlmann, Pizarro, Tannenbaum, and Ditto, 2009).

When encountering difficult ethical challenges, people generally ask themselves the Socratic question "What should I do?" (Victor and Cullen, 1988). And guidance is typically cast in terms of "should." For example, we created a dataset with the ethics codes of Fortune 50 companies sampled in 2013 and counted the number of times the word "should" appeared in each ethics code. We found that "should" appears approximately thirty times on average in each of them. Organizations, it seems, frame the principles to guide managerial conduct in terms of "should." Despite the pervasiveness of having a "should" mindset when confronting moral dilemmas (see also Study 1), in this paper we suggest that approaching ethical dilemmas with such a mindset reduces people's likelihood of generating moral insight. Moral insight consists of 
discovering solutions other than selecting one of the competing ethical options over another. Moral insight encompasses both a cognitive process and a discernible output: it involves the realization that an ethical dilemma might be addressed other than by conceding one set of moral imperatives to another, and it involves the generation of solutions that allow both competing imperatives to be met.

Whereas a "should" mindset may encourage individuals to think analytically in weighing the vying moral claims of the most apparent courses of action, people may often benefit from a more expansive exploration of possible solutions before making a final decision. We propose that considering what one could do shifts people from analyzing and weighing what they assume to be fixed and mutually exclusive alternatives to generating options that might reconcile underlying imperatives. In the famous Heinz dilemma (Kohlberg, 1971), for example, rather than choose between stealing a drug your spouse needs for survival and obeying laws that protect property, some people suggest that Heinz might speak to the druggist who owns the medicine (Gilligan, 1982). When facing ethical dilemmas, shifting individuals from a more conventional "should" mindset to a less conventional "could" mindset encourages greater exploration of possibilities, increasing individuals' ability to discover practical solutions to moral dilemmas that move beyond conceding one or more moral principles to meet another.

The present research makes three main contributions to the literature. First, it extends how ethical dilemmas have traditionally been studied. Prior research on dilemmas has presented individuals with a choice between two possible decisions, showcasing the tension between moral imperatives and revealing the factors that lead individuals to choose one moral value or principle over the other (Kohlberg, 1971; Trevino, 1986; Jones, 1991). Rather than investigate which of two predetermined options is chosen and why, we examine how novel options might be 
generated. Like the dilemmas featured in prior research (Kohlberg, 1971; Rest, Bebeau, Narvez, and Thoma, 1999; Greene, et al., 2001), the real ethical dilemmas that managers face (Badaracco and Useem, 1993; Paine, 1997) typically embody a stark choice. But there are often multiple possible courses of action individuals could potentially devise—-beyond the apparent stark choices — when facing dilemmas. We build on research in ethics (Gilligan, 1982), insight (Smith, 1995; Sternberg and Davidson, 1995; Schilling, 2005), creativity (Csikszentmihalyi and Sawyer, 1995; Sternberg and Davidson, 1995; Miron-Spektor, Gino, and Argote, 2011), decision making (Larrick, 2009), and negotiation (Bazerman, Curhan, Moore, and Valley, 2000; Malhotra and Bazerman, 2007; Harinck and De Dreu, 2008) to show that dilemmas sometimes become tractable when incompatible imperatives are approached in novel ways.

Second, we capture this approach by introducing the concept of moral insight, defined as discovering solutions to moral dilemmas in a way that does not entail conceding one of the colliding ethical imperatives to honor another. Thus far, research linking creativity and ethics has focused on the domain of self-dealing, showing that creativity increases the likelihood that individuals will engage in unethical behavior (Wang, 2011; Gino and Ariely, 2012). When individuals are tempted to cheat for personal gain, creativity sparks greater mental flexibility in justifying unethical actions. But creativity may operate differently in the domain of dilemmas, where individuals face competing moral imperatives rather than an opportunity to gain personally at the expense of ethics. We suggest that for moral dilemmas, creative thinkingprompted through having a "could" mindset—helps individuals formulate a broader set of practical solutions that potentially resolve the collision of ethical imperatives.

Third, we offer a simple-to-implement intervention that helps individuals address moral dilemmas more constructively. Prior research has shown that when people encounter temptations 
to cheat, contemplation and discussion leads people to make more thoughtful, ethical decisions

(Gunia, Wang, Huang, Wang, \& Murnighan, 2012), and that the ethical content of one's thoughts drives behavior (Reynolds, Dang, Yam, and Leavitt, 2014). We suggest that in the context of moral dilemmas, the content of contemplation and conversation matters, particularly in situations where creative problem-solving is helpful in navigating competing imperatives and moral tradeoffs. We show that a possible intervention to change how individuals contemplate and discuss moral dilemmas need not be complex. That is, an intervention as simple as shifting an individual's mindset from contemplating "What should I do?" to "What could I do?" can help individuals generate moral insight that resolves difficult ethical dilemmas.

\section{THEORY AND HYPOTHESES}

Moral dilemmas, as experienced in the workplace or as distilled in research studies, often challenge individuals to prioritize one moral imperative over others when given a forced choice. For example, Kohlberg's Heinz dilemma (1971) asks individuals whether a destitute husband should steal over-priced drugs to save the life of his dying wife, forcing these evaluators to weigh the cost of stealing and breaking the law against the benefit of saving a life. Similarly, the trolley dilemma asks individuals whether they should actively divert a runaway trolley onto a path that would kill one person in order to save five lives (the utilitarian choice), or whether they should choose inaction, spare one life, and leave the train on course to kill five people (the deontological choice) (Thomson, 1986).

Psychology and management research have proposed a variety of theories for explaining individuals' moral reasoning. The cognitive-developmental perspective, for instance, argues that people progress through stages of moral development - from acting based on the punishments associated with each course of action to making a decision based on one's fundamental and 
universal moral principles (Kohlberg, 1971). These stages, in turn, interact with the context of the situation to guide action and reasoning (Kohlberg, 1971; Trevino, 1986). More recently, research has proposed a dual-process model to explain how we think through moral dilemmas. This research has focused on ethical dilemmas that produce a tension between deontological reasoning (which emphasizes individuals' duties) and utilitarian reasoning (which values the greater good for the greatest number) (Greene, et al., 2004). Research testing this model shows that automatic emotional responses drive deontological moral judgments, whereas cognitive processes drive more utilitarian thinking (Greene, et al., 2001; Greene, et al., 2004; Greene, et al., 2008). That is, individuals are less likely to kill one person in order to save five people when emotional systems are driving decisions in the trolley dilemma (Greene, et al., 2001). More recently, some have proposed contingency models, suggesting that how human beings resolve the ethical challenges they face — and the suitability of a given approach — depends on the nature of the ethical challenge (Pizarro and Bloom, 2003; Monin, Pizarro, and Beer, 2007; Bennis, Medin, and Bartels, 2010; Zhong, 2011).

In sum, past research on moral dilemmas has investigated how individuals respond to competing imperatives as they consider what they should do in these situations. The act of thinking about "should" leads individuals to prioritize one moral claim over another and focus on the justifications of their decision. Whereas prior research has focused on the final decision individuals make given the constraint that they can choose only one of the two courses of action provided, our research takes a different approach toward solving dilemmas: we focus on the courses of action individuals generate when they confront a dilemma in different ways. Integrating research in both creativity (Sternberg, 1988; Amabile, 1996; Sternberg and Lubart, 
1999) and insight (Smith, 1995; Sternberg and Davidson, 1995), we examine instances of moral insight, when people move beyond the two most apparent courses of action present in a dilemma.

\section{Developing Moral Insight}

Managerial dilemmas are as often about formulating novel solutions to seemingly intractable conflicts (Toffler, 1986; Paine, 2002; Freeman, 2010) as they are about choosing one moral principle over another. In the opening example, you could decide to tell your boss or simply keep quiet, sacrificing one moral imperative for another, or you might leave an anonymous note for your boss with the key information. While the latter course of action is not without its problems, it does illustrate an alternative path toward resolving moral collisions by honoring moral commitments to both your friend and your employer. Similarly, many other realworld ethical dilemmas promise multiple solutions that either integrate competing objectives or incorporate alternative approaches that change the nature of the problem.

We suggest that when facing moral dilemmas people generate moral insight in the same way they generate insight when facing creativity problems (Isen, Daubman, and Nowicki, 1987). Moral insight consists of novel and practical solutions that move beyond conventional responses requiring the sacrifice of one or more moral principles to meet another. Research on insight problems has indicated that the cognitive processes that lead to solutions neither occur to people immediately on presentation of the problem, nor emerge from analysis and deliberation. Rather, the insight strikes like a bolt — the proverbial "Eureka!" moment—changing the solver's mental representation of the problem (Sternberg, 1988; Seifert, Meyer, Davidson, Patalano, and Yaniv, 1994; Schilling, 2005).

In the context of moral dilemmas, we argue that generating moral insight involves shifting individuals' mental representation of dilemmas away from making a choice between 
forced tradeoffs. Just as insight in problems like Duncker's candle (1945) entails relaxing assumptions that the functions of objects are fixed, moral insight entails relaxing assumptions that there are fixed options from which to choose. There is already some evidence that individuals consider routes to solving these moral dilemmas beyond the choices provided. In Gilligan's classic re-examination of the Heinz dilemma (1982), some individuals thought Heinz should neither steal the drug nor let his wife die, but, instead, should discuss the situation with the druggist. In contrast to research on non-moral insight (Duncker and Lees, 1945) and creativity (Mednick, 1962; Rowe, Hirsh, and Anderson, 2007), which typically examines convergence around a single but non-obvious relationship between objects and concepts, central to our definition of moral insight is the possibility that multiple solutions exist beyond selecting one side of the dilemma or the other.

Put differently, moral insight encompasses both a cognitive process and a discernible output: It involves both the realization that an ethical dilemma might be addressed other than by conceding one set of moral imperatives to meet another. This realization helps generate solutions that allow competing objectives to be met, either through some form of integration or reformulation of the problem itself.

\section{Shifting to a "Could" Mindset}

Existing research has shown the importance of matching cognitive processes to the nature of the ethical challenge faced. For example, extended contemplation has been shown to increase the likelihood that individuals will make ethical decisions in both individual and group contexts, particularly when individuals lack justifications for their unethical behaviors (Caruso and Gino, 2010; Gunia, Wang, Huang, Wang, and Murnighan, 2012; Shalvi, Eldar, and Bereby-Meyer, 2012). However, in other conditions, most notably when another's welfare is pitted against an 
actor's own interests, quick intuitive responses increase the likelihood of ethical choice (Zhong, 2011). In sum, interventions that tailor cognition to the nature of the ethical challenge are essential (Bennis, Medin, and Bartels, 2010; Moore and Tenbrunsel, 2014).

In the context of moral dilemmas, individuals generally approach these problems by contemplating what they should do. We propose that despite the prevailing tendency to use this approach when facing moral dilemmas (see Study 1), shifting individuals' contemplation toward what they could do changes both their perception of the dilemma and the solutions that they reach. Because the question "What should you do?" implies selecting one moral path, "should" mindsets may lead individuals to focus on weighing and choosing one of two possible courses of action in these dilemmas. Consequently, thinking about "shoulds" may lead people to satisfice in settling for a solution that meets the primary ethical priority while neglecting the other value.

In contrast, a "could" mindset may shift individuals to reconceive the problem as one that does not necessarily involve forced tradeoffs. Langer and Piper (1987) found that considering what objects could be as opposed to what objects were helped individuals transcend the problem of functional fixedness, or the inability to use objects beyond the purposes for which they were originally designed (Luchins, 1942; Isen, Daubman, and Nowicki, 1987). For example, when confronted with the need to erase a mark without using an eraser, individuals who merely considered what objects could be were more likely to recognize that a rubber band could be used in lieu of an eraser, compared to those who considered what these objects were. Just as thinking about what objects could be influenced individuals to overcome the rigidity of considering only conventional uses of objects, we propose that contemplating what one could do in moral dilemmas helps individuals think beyond the rigidity of making forced tradeoffs between moral 
principles, thus imagining how ostensibly competing imperatives might be less incompatible (see Figure 1 for conceptual model).

Hypothesis 1: A “could" mindset decreases the extent to which competing objectives appear incompatible relative to a "should" mindset.

We also argue that "could" carries the connotation of multiple possibilities. That is, part of the reason that individuals were able to reach creative solutions after considering what objects could be is that the mental exercise helped individuals think about alternative uses for the focal object (Langer and Piper, 1987). Similarly, considering what individuals could do in moral dilemmas will not only relax the assumptions that there is a choice to be made and that the imperatives are necessarily incompatible, but also unlock individuals' ability to engage in divergent thinking, so they consider multiple solutions to problems (McCrae, 1987; Runco, 1991; Silvia, Winterstein, Willse, Barona, Cram, Hess, Martinez, and Richard, 2008).

Hypothesis 2: A "could" mindset increases divergent thinking—or the formulation of multiple solutions — in moral dilemmas relative to a "should" mindset.

Because divergent thinking involves thinking "without boundaries" or "outside the box" (Thompson, 2008, p. 226), consideration of multiple solutions is helpful in discovering more insightful and creative solutions (Baer, 1994). By considering multiple possible solutions, divergent thinking helps individuals make new connections and associations (Guilford, 1968; Guilford, 1982), reducing individuals' propensity to settle upon obvious answers and increasing their ability to reach innovative solutions to problems (Williams, 2004). Given the link between divergent exploration and organizational creativity (Woodman, Sawyer, and Griffin, 1993), we expect that having a "could" mindset will trigger individuals to consider multiple solutions that will eventually help them find more novel resolutions to the dilemma. 
In research on interpersonal conflict, thinking creatively beyond conventional options has been found to generate integrative solutions (Kurtzberg, 1998; De Dreu, Giacomantonio, Shalvi, and Sligte, 2009), so we adapt principles from negotiation to study the intrapersonal conflict that individuals experience when confronted with ethical dilemmas. When negotiators perceive their environment as competitive, they often assume that goals across negotiating parties are negatively related, implying that they must make distributive tradeoffs in order to find solutions (Carnevale and Probst, 1998; Tjosvold, 1998). This competitive mindset often leads individuals to reach purely distributive solutions that assume the size of the economic pie as given (Baron, Bazerman, and Shonk, 2006; Malhotra and Bazerman, 2007; Demoulin and Teixeira, 2010; Fisher, Ury, and Patton, 2011). In contrast, negotiators who realize the potential to reconcile competing sides are more likely to discover integrative solutions that expand the size of the overall pie and often maximize outcomes for both negotiating parties (Brandenburger and Nalebuff, 1996; De Dreu, 2003; Harinck and De Dreu, 2008).

Insert Figure 1 about here

Additionally, research shows that adopting a paradoxical framework (Lewis, 2000), or "mental templates used to embrace seemingly contradictory" elements of a task (Miron-Spektor, Gino, and Argote, 2011; pg. 229), generates more innovation (Smith and Tushman, 2005; Gebert, Boerner, and Kearney, 2010) and creativity (Carnevale and Probst, 1998; Miron-Spektor, Gino, and Argote, 2011). That is, casting seemingly paradoxical or incompatible goals as potentially reconcilable helps individuals consider ways to meet both objectives, rather than satisficing to meet just one (Austin and Vancouver, 1996; Lüscher and Lewis, 2008). Taken 
together, we propose that applying a "could" mindset toward ethical dilemmas increases moral insight, enhancing individuals' ability to look beyond forced tradeoffs, prompting them to develop a wider set of possible options, and ultimately helping them formulate solutions that uphold colliding moral imperatives.

Hypothesis 3a: A "could" mindset relative to a "should" mindset increases the propensity to formulate moral insight solutions.

Hypothesis 3b: The effect of a "could" mindset on the propensity to formulate moral insight solutions is mediated by the extent to which individuals engage in divergent thinking.

Hypothesis 3c: The effect of a "could" mindset on the propensity to formulate moral insight solutions is mediated by the extent to which multiple objectives appear less incompatible.

\section{Overview of the Present Research}

We test our predictions regarding the impact of a "could" mindset on generating moral insight across four experiments. Study 1 shows that people intuitively ask themselves "What should I do?" when contemplating moral dilemmas. Despite the tendency to approach moral dilemmas this way, Studies 2 through 4 show that asking "What could I do?" leads individuals to think more expansively about dilemmas, generating moral insight. In Study 2, we find that a “could" mindset helps individuals view ostensibly incompatible ethical goals as less incompatible relative to either a "should" or "would" mindset. Study 3 reveals that compared to having a "should" mindset, contemplating "What could I do?" leads individuals to engage in more divergent thinking as they explore possible options, helping them formulate a greater range of possible solutions. Finally, Study 4 shows that adopting a "could" mindset in interpersonal 
contexts helps individuals generate moral insight when discussing a moral dilemma with each other.

\section{STUDY 1: DEFAULT APPROACH TO ETHICAL DILEMMAS}

The goal of this study was to examine how individuals intuitively approach moral dilemmas compared to amoral dilemmas.

\section{Participants}

We recruited sixty participants $\left(M_{\text {age }}=32.38, S D=13.39 ; 38 \%\right.$ female $)$ on Amazon's Mechanical Turk for a study that asked them to provide their thought process on hypothetical scenarios and paid them $\$ 0.50$ in Amazon.com credit for completing the five-minute study. Past research has shown that the Mechanical Turk service provides reliable data for research purposes (Buhrmester, Kwang, and Gosling, 2011).

\section{Design and Procedure}

Participants were randomly assigned to read either two moral dilemmas (e.g., the Heinz dilemma) or two amoral dilemmas (See Appendix A). They were then instructed to complete the following question with a word or phrase that best captured what they were thinking as they considered their response to each dilemma: "What ___ I do?" Two independent raters blind to the purpose of the study then coded each response based on whether they contained the word "should," "could/can," or "will/would." Because we achieved good interrater reliability on the percentage of responses across the dilemmas that contained the word "should" $\left(\mathrm{ICC}_{2}=.99, p<\right.$ $.001)$ or "could" $\left(\mathrm{ICC}_{2}=.99, p<.001\right)$, we averaged the ratings between the two coders.

We hypothesized that participants would be more likely to use the word "should" rather than the word "could" to complete the question when approaching moral dilemmas. We also expected the use of "should" to be more frequent in moral rather than in amoral dilemmas. 


\section{Results and Discussion}

Participants considered "shoulds" a greater percentage of the time in a moral context ( $M$ $=61.54 \%, S D=.36)$ than in an amoral context $(M=36.03 \%, S D=.35), t(58)=2.76, p=.008, d$ $=.72$. In contrast, participants who read moral dilemmas considered "coulds" $(M=8.65 \%, S D=$ .23) a smaller percentage of the time compared to those who read amoral dilemmas $(M=$ $27.94 \%, S D=.28), t(58)=2.83, p=.006, d=.74$. These percentages also show that people generally approach moral dilemmas using a "should" mindset rather than a "could" mindset, using the former over $61 \%$ of the time and the latter less than $9 \%$ of the time. ${ }^{1}$

Insert Table 1 about here

These results indicate that people intuitively consider "What should I do?" more frequently when confronting moral dilemmas compared to amoral dilemmas, and that the "should" mindset is the most common mindset people adopt when contemplating moral dilemmas. The following studies explore the effectiveness of adopting a "should" mindset relative to a "could" mindset when encountering a series of ethical dilemmas.

\section{STUDY 2: GOAL COMPATIBILITY}

Whereas individuals have a natural propensity to consider the actions they "should" take when confronting ethical dilemmas, Study 2 examines the actual effect of three main modes of thought — should, would, and could — on the extent to which individuals view the competing imperatives featured in ethical dilemmas as compatible. We included a "would" mindset to test if adopting any mindset other than a "should" mindset changes the way people perceive dilemmas.

\footnotetext{
${ }^{1}$ The remaining $30 \%$ of individuals contemplated what "would" or "will" I do.
} 
We hypothesized that relative to having a "should" or "would" mindset, having a "could" mindset would help individuals realize that the seemingly competing goals are in fact more compatible (Hypothesis 1). We based this hypothesis on prior research linking "could" mindsets to creativity and more expansive thinking (Langer and Piper, 1987).

\section{Participants}

Two hundred eighty individuals $\left(M_{\text {age }}=35.07\right.$ years; 64\% female $)$ recruited through Amazon's Mechanical Turk participated in an online study in exchange for $\$ 0.75$.

\section{Design and Procedure}

Participants contemplated a series of four ethical dilemmas and were randomly assigned to answer the question "What 'could,' 'should,' or 'would' you do?" for each of the four dilemmas (see Dilemmas 1-4 in Appendix B). Participants then answered a series of survey questions that measured the extent to which they believed the two primary goals of each dilemma were incompatible with one another.

\section{Measure}

Goal compatibility. After providing responses to each of the dilemmas, participants rated the extent to which the two main objectives of the dilemma were incompatible (1= "It is definitely possible to do both at the same time;" 2 = "It is possible to do both at the same time;" $3=$ "It is not possible to do both at the same time;" $4=$ "It is definitely not possible to do both at the same time"). For example, participants who read the Heinz dilemma were asked, "To what extent do you think 1) saving your spouse's life and 2) not breaking the law (not stealing the drug) are compatible/incompatible?".

\section{Results}


To test the impact of the participants' mindset on the extent to which they thought the competing goals in each of these dilemmas were compatible, we conducted a repeated-measures analysis of variance (ANOVA) with the mindset (should vs. would vs. could) as the betweensubjects factor and ratings across the four dilemmas as the within-subjects factor (repeated measures on dilemma). The results revealed a significant main effect of the participants' mindset on perceived goal compatibility, $F(2,277)=6.55, p=.002, \eta_{\mathrm{p}}{ }^{2}=.05$. Post-hoc pairwise comparisons suggest that participants viewed these goals as less incompatible when contemplating "What could I do?" $(M=1.49, S D=.53)$ compared to "What should I do?" $(M=$ $1.70, S D=.53, p=.007)$ and "What would I do?" $(M=1.77, S D=.52, p=.001)$. There was no difference in goal compatibility ratings between those who contemplated "What should I do?" and "What would I do?" $(p=.38)$.

We also found a main effect of dilemmas, $F(3,831)=23.37, p<.001, \eta_{\mathrm{p}}^{2}=.08$, suggesting that participants perceived some of the dilemmas as featuring more incompatible goals than others. Post-hoc analyses revealed that participants found the goals in the first dilemma to be less incompatible $\left(M_{l}=1.42, S D_{l}=1.00, p<.08\right)$ and those in fourth dilemma to be more incompatible $\left(M_{4}=2.00, S D_{4}=.85, p<.001\right)$ than those in the other dilemmas $\left(M_{2}\right.$ $\left.=1.65, S D_{2}=.99, M_{3}=1.55, S D_{4}=.87\right)$. The interaction between participants' mindsets and type of dilemma did not reach statistical significance, $F(6,831)=1.74, p=.11$.

\section{Discussion}

Results from this study support our first hypothesis that contemplating "coulds" helps individuals perceive seemingly incompatible objectives in ethical dilemmas as less incompatible relative to contemplating "shoulds." The lack of evidence that "should" and "would" mindsets differ in their impact suggests that the impact of a "could" mindset is not driven by the 
possibility that "should" mindsets lead individuals to perceive competing objectives as more incompatible relative to baseline.

\section{STUDY 3: “COULD” MINDSET AND MORAL INSIGHT}

Although Study 2 revealed how people think about moral dilemmas differently when in a "could" versus "should" mindset, these findings do not provide information on how "could" mindsets influence the solutions that individuals reach. In this study, participants considered a series of dilemmas and indicated either what they "could" or "should" do in response before finally reporting what they "would" do. We hypothesized that relative to a "should" mindset, a "could" mindset would influence individuals to engage in divergent thinking (Hypothesis 2), better equipping individuals to produce a broader range of possible solutions that conceded neither imperative embedded in the dilemma (Hypotheses $3 a$ and $3 b$ ).

\section{Participants}

Two hundred six individuals ( $M_{\text {age }}=35.02$ years; $59.2 \%$ female) recruited through Amazon's Mechanical Turk participated in an online study in exchange for $\$ 1.50$.

\section{Design and Procedure}

Participants were randomly assigned to adopt either a "could" mindset or "should" mindset while contemplating a series of four ethical dilemmas (see Dilemmas 1-4 in Appendix B). Those randomly assigned to adopt a "could" mindset provided written responses to the question "What could you do?" for each of the four dilemmas, whereas those assigned to think in a "should" mindset provided written responses to the question "What should you do?"

All participants then answered the question "What would you do?" After these questions, participants then answered follow-up questions about their responses to each dilemma. Two independent coders blind to the study's hypotheses rated each of participants' written responses 
based on their creativity and whether the proposed solutions satisfied competing values for each of the dilemmas.

\section{Measures}

Manipulation check. As a manipulation check, two independent coders blind to the hypotheses of the study recorded the number instances in which participants used the words "could" and "should" in their written responses to the question "What [should/could] I do?" across the four dilemmas. Because we achieved high inter-rater reliability, we averaged the ratings from the two raters for the number of times participants mentioned "could" $\left(\mathrm{ICC}_{2}=.92, p\right.$ $<.001)$ and "should" $\left(\mathrm{ICC}_{2}=.93, p<.001\right)$.

Divergent thinking. We measured divergent thinking based on one self-reported measure and another measure based on two independent coders. Participants self-reported the number of solutions they considered as they answered the question "What [should/could] I do?" Separately, two independent coders rated the extent to which participants' solutions were "outside of the box" and "spanned different categories of solutions" (1= "not at all"; $4=$ "somewhat"; 7 = “extremely") based on Amabile's (1996) consensual assessment technique. We aggregated the two rater's responses into a single measure since the two raters achieved good reliability $\left(\mathrm{ICC}_{2}=.82, p<.001\right)$.

Moral insight solutions. Two independent coders rated participants' responses to the question "What would you do?" for each of the four dilemmas based on whether that solution resolved the underlying tension present in the dilemma. For example, we coded solutions that fell outside of the conventional responses "steal the drug" or "do not steal the drug" and that sought to meet both objectives in the dilemmas as evidence of moral insight. For example, moral insight solutions in response to the Heinz dilemma included "bring the story to the local media" and 
"start a charitable foundation for my spouse." Because we obtained high reliability between raters for the total number of morally insightful solutions generated across the four dilemmas, we averaged these ratings into a single measure of moral insight solutions $\left(\mathrm{ICC}_{2}=.81, p<.001\right)$.

\section{Results}

Table 2 presents the means, standard deviations, and correlations of the variables we measured.

Manipulation check. We found that those in the "could" mindset used the word "could" $(M=.90, S D=1.02)$ more times in their responses than those in a "should" mindset $(M=.24$, $S D=.45), t(204)=6.08, p<.001, d=.85$, whereas those in the "should" mindset wrote more responses containing the word "should" $(M=.29, S D=.67)$ than did those in a "could" mindset $(M=.12, S D=.36), t(204)=2.35, p=.02, d=.33$, suggesting that our manipulation was indeed effective.

Divergent thinking. We conducted a repeated-measures ANOVA with participants' mindset (should vs. could) as the between-subjects factor, the dilemma as the within-subjects factor, and the number of solutions participants reported considering for each dilemmas as the dependent variable. Across the four dilemmas, participants reported having considered more solutions in the "could" mindset $(M=5.06, S D=1.75)$ compared to the "should" mindset $(M=$ $4.41, S D=1.07), F(2,194)=10.70, p<.001, \eta_{\mathrm{p}}{ }^{2}=.05$. We also found a significant interaction between the dilemma type and mindset, $F(2,582)=6.53, p<.001, \eta_{\mathrm{p}}{ }^{2}=.03$.

We conducted a similar analysis based on two independent coders' ratings of the extent to which participants engaged in divergent thinking on average across the four dilemmas and found that having a "could" mindset increased divergent thinking $(M=3.17, S D=1.22)$ relative to having a "should" mindset $(M=2.37, S D=1.02), F(2,203)=26.36, p<.001, \eta_{\mathrm{p}}{ }^{2}=.12$. We 
also found a significant interaction between the dilemma type and mindset, $F(2,609)=6.48, p=$ $.04, \eta_{\mathrm{p}}^{2}=.01$.

Moral insight solutions. Based on two coders' ratings of participants' solutions in response to the question "What would you do?", we found that a "could" mindset $(M=.97, S D=$ .89) generated more moral insight solutions across the four ethical dilemmas relative to a "should" mindset $(M=.68, S D=.75), t(203)=2.53, p=.01, d=.35$.

Mediation analysis. We examined whether divergent thinking mediated the effect of a “could" mindset on participants' ability to generate moral insight solutions (Baron \& Kenny, 1986). A "could" mindset was positively associated with independent coders' ratings of divergent thinking $(\beta=.21, t=3.06, p=.002$; see Table 3 ). When controlling for divergent thinking, the effect of adopting a "could" mindset was reduced to non-significance (from $\beta=.18, t=2.53$, $p=.01$ to $\beta=.009, t=.21, p=.83)$, and divergent thinking predicted participants' ability to generate moral insight solutions $(\beta=.79, t=17.90, p<.001)$. A bootstrap analysis indicated that the $95 \%$ bias-corrected confidence interval for the size of the indirect effect excluded zero $(.10, .45)$, suggesting a significant indirect effect (MacKinnon, Fairchild, and Fritz, 2007).

Insert Tables 2 and 3 about here

\section{Discussion}

These results support Hypothesis 2, which predicted that relative to those in a "should" mindset, "could" thinkers would be more likely to engage in divergent thinking as they contemplated solutions to difficult ethical dilemmas. Consequently, when asked what they "would" do, the "could" thinkers were better able to generate more moral insight solutions that 
did not simply select one side of the dilemmas at the expense of the other, thereby supporting Hypotheses $3 \mathrm{a}$ and $3 \mathrm{~b}$. These results support the idea that generating moral insight encompasses a process of formulating multiple options and a resulting outcome- the formulation of moral insight solutions.

\section{STUDY 4: “COULD” CHANGES THE CONVERSATION}

Studies 2 and 3 showed that "could" mindsets changed individuals' perceptions of ethical dilemmas as well as their solutions when they contemplated ethical challenges privately. Because individuals often discuss ethical challenges with others, we investigated in Study 4 the extent to which a "could" mindset changes exploration of viable alternatives in interpersonal discussions. We conducted this study in a laboratory setting and incentivized individuals in dyads to adopt either a "could" or "should" mindset. We expected to find that a "could" mindset would lead individuals to perceive seemingly competing objectives as more compatible (Hypothesis 3a). Furthermore, based on research showing that people are more likely to find solutions to problems when they view objectives or goals as compatible rather than incompatible (Austin and Vancouver, 1996), we predicted that viewing these objectives as less incompatibleas triggered by a "could" mindset—would generate greater exploration of alternatives and more solutions that meet both moral imperatives (Hypothesis 3c).

\section{Participants}

Two hundred two individuals $\left(M_{\mathrm{age}}=22.96\right.$ years; $49.0 \%$ female $)$ forming one hundred one dyads participated in a lab study at a university in the northeastern United States in exchange for $\$ 20$ and the opportunity to earn an additional $\$ 2$ based on their execution of instructions provided.

\section{Design and Procedure}


Participants were randomly assigned to adopt either a "could" mindset or "should" mindset while discussing an ethical dilemma with a randomly assigned partner. All participants read an adaptation of the analyst's dilemma (Badaracco and Useem, 1993), which involved deciding whether to tell their boss strictly confidential information that would help the company, but hurt the roommate who divulged this information (see Dilemma 4 in Appendix B). Dyads were given the opportunity to discuss this dilemma for fifteen minutes in a virtual chat room and were informed they could end the conversation earlier if they felt that they had finished discussing the dilemma in the allotted time. Those randomly assigned to adopt a "could" mindset received $\$ 2$ if they asked their partner "What could we do?" during the interaction, whereas "should" mindset participants received $\$ 2$ if they asked their partner "What should we do?" At the end of the discussion, all participants then answered the question, "What would you do?" Participants were instructed that they did not need to agree with their partner on the ultimate solution.

Participants then answered a series of survey questions measuring their perception of their own solutions. They assessed the extent to which they judged the multiple objectives presented in this dilemma as incompatible, the extent to which their proposed solution met these objectives, and their perceived creativity of their proposed solutions.

Two independent coders blind to the hypotheses of the study documented the number of 1) different possible actions that were discussed during the conversation and 2) ultimate solutions participants selected. Solutions that fell outside of the response "tell my boss" or "keep the information confidential" and that simultaneously sought to both "protect/help the roommate" and "help the boss/company" were considered evidence of moral insight (see Table 4 for examples). 
One hundred one independent coders then rated each of the unique category of solutions provided based on the perceived creativity and quality of the solution.

\section{Measures}

Manipulation check. Two independent coders blind to the hypotheses of the study recorded whether participants used the words "could" and "should" in the conversations. The agreement between raters was significantly above and beyond chance agreement $\left(\kappa_{\text {could }}=.74\right.$, $\left.p_{\text {could }}<.001, \kappa_{\text {should }}=.50, p_{\text {should }}<.001\right)$.

Duration of discussion. We measured the amount of time that participants spent conversing with their partners about the moral dilemma.

Moral insight solutions discussed. These coders also identified instances during each conversation when individuals suggested alternative solutions that satisfied competing objectives (help/protect roommate and help boss/company) and classified each of these as evidence of moral insight based on the type of action recommended (see Table 4). Because we obtained high inter-rater reliability between the two coders $\left(\mathrm{ICC}_{2}=.76, p<.001\right)$, we averaged the number of moral insight solutions discussed during the conversations into a single item.

One hundred one independent raters blind to the hypotheses also judged these categories of alternative solutions (as presented in Table 4) based on the creativity ( 1 = "Not at all creative" to $7=$ "Extremely creative") and quality of the solution ( $1=$ "Extremely bad solution," $4=$ "Neither good nor bad," 7 = "Extremely good solution"). Because factor analyses revealed that the two typical responses clustered together as a group and the atypical responses clustered together as a group, we present the means averaged across categories (moral insight solutions vs. common solutions). 
Insert Table 4 about here

Perceived incompatibility of objectives. After providing an ultimate solution, participants rated the extent to which "maintaining the confidentiality agreement with your roommate" and "informing your boss about the news" were incompatible ( $1=$ "It is definitely possible to do both at the same time;" $2=$ "It is possible to do both at the same time;" $3=$ "It is not possible to do both at the same time;" 4= "It is definitely not possible to do both at the same time").

Perception of solutions. Participants then rated the extent to which they believed their solutions met multiple objectives presented in the dilemma ( $1=$ "Met only one objective," $7=$ "Met all objectives"), and were creative (1= "Not at all," 7= "Extremely").

Thoughtfulness of solution. The same two independent coders blind to the hypotheses rated the thoughtfulness of each solution ( $1=$ "Not at all" to $7=$ "Extremely"). Since the two raters achieved moderate reliability $\left(\mathrm{ICC}_{2}=.55, p<.001\right)$, we averaged the two coder's ratings to obtain a single measure of thoughtfulness.

Moral insight solution selected. Two independent coders identified all unconventional solutions that satisfied competing goals into the same categories that were used for the conversations (see Table 4 for examples). Solutions were coded as morally insightful if they were classified in at least one of these categories. Because the two raters achieved high agreement $(\kappa=.84, p<.001)$, we averaged the two coder's ratings to obtain a single rating of moral insight solution.

\section{Results}

Manipulation check. Participants in the "should" mindset were more likely to mention "should" ( $M=99.0 \%, S D=.07)$ in their discussion compared to those in the "could" mindset $(M$ 
$=29.8 \%, S D=.28), t(99)=16.53, p<.001, d=3.32$; similarly, those in the "could" mindset were also more likely to mention "could" $(M=94.2 \%, S D=.16)$ in their discussion with their partners than those with a "should" mindset $(M=7.1 \%, S D=.18), t(99)=25.89, p<.001, d=$ 5.20 .

Duration of discussion. Dyads discussing what they "could" do spent more time discussing the dilemma $(M=601.91$ seconds, $S D=310.5)$ than did dyads discussing what they "should" do $(M=482.85$ seconds, $S D=246.97), t(100)=2.17, p=.03, d=.43$.

Moral insight solutions discussed. Importantly, the "could" mindset increased divergent thinking that elicited more alternative responses on average from individuals $(M=1.08, S D=$ $.88)$ than did the "should" mindset $(M=.62, S D=.67)$ based on coding of all ideas generated during the discussions, $t(99)=2.91, p=.004, d=.58($ see Table 4$)$.

Indeed, a separate group of one hundred one independent raters found these moral insight solutions to be more creative $(M=4.31, S D=.91)$ and higher in quality $(M=4.89, S D=.88)$ than solutions that entailed selecting one imperative over the other (that is, either keeping the information confidential or telling the boss $)\left(M_{\text {creative }}=1.90, S D_{\text {creative }}=1.12 ; M_{\text {quality }}=3.27\right.$, $\left.S D_{\text {quality }}=1.09\right), t_{\text {creative }}(100)=20.95, p_{\text {creative }}<.001, d_{\text {creative }}=4.19, t_{\text {quality }}(100)=11.60, p_{\text {quality }}<$ $.001, d_{\text {quality }}=2.32$. We present means separately in Table 4 .

Perceived incompatibility of objectives. Participants in the "could" mindset rated the objectives in this dilemma as less incompatible $(M=1.44, S D=.86)$ than those in the "should" mindset $(M=1.76, S D=.88), t(199)=2.57, p=.01, d=.36$

Perception of solutions. Participants in the "could" mindset rated their own solutions as more creative $(M=3.61, S D=1.78)$ than those in the "should" mindset $(M=2.84, S D=1.74)$, $t(199)=3.10, p=.002, d=.44$. Similarly, those in the "could" mindset also believed their 
solutions met more objectives $(M=4.35, S D=2.01)$ compared to those in the "should" mindset $(M=3.60, S D=1.94), t(199)=2.72, p=.007, d=.39$.

Insert Table 5 about here

Thoughtfulness of solution. Two independent coders rated "could" solutions as more thoughtful $(M=3.90, S D=1.32)$ than "should" solutions $(M=3.33, S D=1.51), t(197)=2.86, p$ $=.005, d=.41$.

Moral insight solutions selected. Based on ratings of two independent coders, those with a "could" mindset were more likely to propose a solution that would simultaneously protect the friend and provide critical information to their boss $(60.2 \%)$ relative to those in a "should" mindset $(35.3 \%), t(198)=3.74, p<.001, d=.53$.

Mediation analysis. We examined whether perception of greater incompatibility of competing objectives would mediate the effect of adopting a "could" mindset on the propensity to find moral insight solutions that address these objectives (Baron \& Kenny, 1986). Adopting a "could" mindset was negatively associated with perceptions of goal incompatibility $(\mathrm{B}=-.31, t=$ 2.53, $p=.01$ ) (see Table 4). When controlling for perceptions of goal compatibility, the effect of adopting a "could" mindset was significantly reduced (from $\mathrm{B}=.25, t=3.82, p<.001$ to $\mathrm{B}=$ $.20, t=3.19, p=.002$ ), and perceptions of goal incompatibility predicted the likelihood of proposing a moral insight solution $(\mathrm{B}=-.16, t=4.45, p<.001)$. A bootstrap analysis indicated that the $95 \%$ bias-corrected confidence interval for the size of the indirect effect excluded zero $(.01, .10)$, suggesting a significant indirect effect (MacKinnon et al., 2007). 
Insert Table 6 about here

\section{Discussion}

Results from this study support our predictions in Hypotheses $3 \mathrm{a}$ and $3 \mathrm{c}$ that adopting a "could" mindset helps individuals perceive seemingly incompatible goals in ethical dilemmas as more compatible, improving generation of moral insight solutions that satisfied multiple objectives. Additionally, as further support of Hypothesis 2, dyads of individuals adopting a "could" mindset engaged in longer discussions and explored more options when they discussed possible courses of actions in these dilemmas than did dyads adopting a "should" mindset.

\section{GENERAL DISCUSSION}

Given that moral dilemmas are vexing and difficult to solve because they often force individuals to prioritize one moral imperative over another, we consider interventions aimed to help individuals think more expansively about possible solutions. We introduce the concept of moral insight and demonstrate its importance in the context of moral dilemmas. Moral insight encompasses (1) a process of realizing that ostensibly competing imperatives are not necessarily incompatible and (2) outputs in the form of solutions that meet both imperatives. We show that individuals' mindsets strongly influence whether they generate moral insight when they contemplate moral dilemmas.

Across four studies, we demonstrate that although individuals intuitively approach ethical dilemmas with a "should" mindset (Study 1), shifting individuals to consider what they could do helps them realize that seemingly incongruous objectives (e.g., saving a life and acting lawfully) are in fact less incompatible than they first appear (Studies 2 and 4). Furthermore, having a "could" mindset expands the set of possibilities produced (Studies 3 and 4), ranging beyond the 
most apparent solutions that require making forced tradeoffs between moral imperatives. Adopting a "could" mindset helps individuals generate moral insight not only in private contemplations, but also in social contexts (Study 4). Together, these findings show that a shift in mindset from "What should I do?" to "What could I do?" leads to moral insight, enabling people to formulate solutions that resolve the tension between competing objectives across a series of ethical dilemmas.

\section{Theoretical Implications}

The present work contributes to research on behavioral ethics, creativity, and decision making. Recent research on ethics in organizations has largely focused on the antecedents and consequences of misconduct (Tenbrunsel, 1998; Schweitzer, Ordóñez, and Douma, 2004; Mead, et al., 2009; Tenbrunsel, et al., 2010; Bazerman and Gino, 2012), investigating the factors that influence individuals who care about morality to act unethically (Bryan, Adams, \& Monin, 2012; Covey, Saladin, \& Killen, 1989; Hershfield, Cohen, \& Thompson, 2012; Jordan, Mullen, \& Murnighan, 2011; McCabe, Trevino, \& Butterfield, 2001), and the impact of these actions in the workplace (Greenberg, 1993; Pfarrer, Decelles, Smith, and Taylor, 2008; Palmer, 2012). More recently, the field has examined the impact of tools to help employees and managers make more ethical decisions when facing temptations to cheat (Gino and Margolis, 2011; Shu, et al., 2012; Moore and Gino, 2013). Although the tendency to choose wrong over right has understandably drawn the majority of research attention in the wake of a long list of business scandals over the last two decades, managers and employees in organizations must also contend with another comparably important category of ethical challenge: when right collides with right. However, recent research has been relatively silent in exploring how people might approach these dilemmas. 
How people most effectively handle different types of ethical challenges - conflict between right and wrong, on the one hand, and conflict between two rights (or the lesser of two evils), on the other-is illustrated by the contrasting effect of creativity. Thus far, research on ethical decision making and creativity has focused on opportunities to do wrong in order to benefit the self, finding that creative thinking makes it more likely for people to cheat (Wang, 2011; Gino and Ariely, 2012; Beaussart, Andrews, and Kaufman, 2013). In contrast, we find that in decision making contexts that pit two or more competing moral principles against one another, approaching the problem with a creative mindset is conducive to discovering solutions that honor both of the competing moral imperatives. We find that moral insight is particularly important in preventing the inherent tension between moral values from forcing individuals to automatically select one option over the other before even considering other possible options. We highlight how adopting a "could" mindset helps individuals utilize their creativity constructively to explore alternative solutions to moral dilemmas.

The concept of moral insight introduced in this paper integrates research from insight (Smith, 1995; Sternberg and Davidson, 1995), decision making (Larrick, 2009), negotiations (Harinck and De Dreu, 2008), and creativity (McCrae, 1987; Runco, 1991). Moral insight is generated by subtle shifts in how moral dilemmas are approached, provoking (1) recognition that the incompatibility between moral imperatives is not fixed, (2) efforts to think divergently about resolving the conflict among those imperatives, and (3) solutions that meet the competing objectives or otherwise resolve the tension between them. Creativity, our findings show, can enhance - rather than undermine - the pursuit of moral courses of action in some domains.

Put differently, our findings turn Kant's famous principle of "ought implies can" on its head. The principle implies that for a moral obligation to be valid, the action it requires must be 
possible (Kant, 1998). Our findings show that "could implies ought" in the context of moral dilemmas. That is, thinking about what might be possible unleashes the potential to satisfy more "oughts" than would be the case if "ought" were considered first.

\section{Practical Implications}

Whereas prior research in ethics has focused on interventions that might mitigate misconduct in organizations, our research seeks to identify simple-to-implement solutions that equip individuals for a different type of ethical challenge - moral dilemmas. The study of ethical dilemmas to date has largely focused on thought experiments that test how individuals analyze, weigh, and adjudicate the conflicting imperatives in a dilemma (for example, Toffler, 1986; Greene, et al., 2001). Our findings shift the study of dilemmas to reveal how employees and teams might devise practical solutions that resolve the inherent tension in a dilemma. Rather than assume a fixed contest that requires adjudication and a tradeoff, our research indicates that ethical dilemmas permit multiple solutions. In fact, the extent to which individuals can find solutions that do not compromise one moral imperative for another depends on their ability to recognize that competing moral imperatives are not necessarily incompatible.

Building on research investigating the impact of contemplating situations that tempt individuals to cheat (Zhong, 2011; Gunia, et al., 2012; Shalvi, Eldar, and Bereby-Meyer, 2012; Moore and Tenbrunsel, 2014), we show that the content of contemplation matters, particularly in situations where creative problem-solving is helpful in navigating among competing objectives and tradeoffs. In particular, shifting the content of the contemplation or conversation does not require a substantial change. Merely shifting the consideration of what individuals should dothe default approach to moral dilemmas - toward what individuals could do helps individuals relax the constraints of the dilemma and generate moral insight. 


\section{Limitations and Directions for Future Research}

Our research has some limitations with implications for future research. First, it is possible that the instructions to adopt either a "should" or "could" mindset created demand effects that either led individuals in "could" mindsets to consider more solutions than they otherwise would have on their own, or influenced those in the "should" mindset to restrict their thinking to answer the question posed more directly. To address this concern, we asked participants an open-ended question at the end of each experiment regarding what they thought the experiment was about. We did not find any instances in which participants in the "could" mindset condition found consideration of "coulds" as a leading question or any evidence that participants suspected we were investigating the impact of adopting a "could" mindset on the creativity of their solutions. Furthermore, to avoid the confound that "could" mindsets open possibilities because those in the "should" mindset were merely following instructions justifying their decisions, participants in Studies 3 and 4 not only answered what they "should" or "could" do, but also indicated what they "would" do, giving individuals in both situations the opportunity to provide solutions that are outside the set of conventional responses.

Second, more work is needed to understand how shifting to a "could" mindset has differential impacts on the solutions reached for different types of moral dilemmas. For example, some dilemmas do not involve the decision maker directly, and the consequences of those decisions have only an indirect impact on the decision maker. In contrast, other dilemmas feature other tradeoffs that involve direct costs or benefits to the individual deciding the course of action. Further research is needed to understand how the actors involved in the dilemma influence the effect of "could" thinking. Additionally, in the dilemmas featured in our research, individuals faced a conflict between two morally defensible options (or two morally objectionable options), 
and moral insight allowed individuals to integrate the underlying moral imperatives. More research is needed to understand how a "could" mindset influences judgments and decisions in other moral domains. For example, when self-gain is an option (at the expense of ethical principles), "could" may lead individuals to contemplate "What could I get away with?"

Lastly, our studies were conducted online and in the lab. Although participants contemplated ethical dilemmas based on real situations, they did not act in the actual contexts of the ethical dilemmas. That is, some of the solutions classified as moral insights may not have been feasible, depending on the real context of these problems. Because our studies investigate problem solving in laboratory and online experiments, future research is needed to investigate how employees respond to ethical dilemmas in real organizations. Additionally, investigation of this question in organizations can also help answer the question of how adopting "could" mindsets fairs in contexts where dilemmas are dynamic_-ever changing in response to the decisions that individuals make - and where individuals are collaborating with others, who may all have different mindsets and perspectives, to find a joint solution.

\section{CONCLUSION}

Our research reveals how a significant class of ethical challenges, often overlooked in efforts to understand misconduct, benefit from the application of unconventional thinking. When encountering ethical dilemmas, shifting one's mindset from "What should I do?" to "What could I do?" generates moral insight: the realization that ostensibly competing values are not entirely incompatible, exploration of more possible solutions beyond the apparent constraints of the problem provided, and formulation of solutions that satisfy multiple moral imperatives. Although our natural inclination is to contemplate dilemmas with a "should" mindset, adopting a "could" mindset opens a broader range of possibilities and brings us one step closer to moral insight. 


\section{REFERENCES}

Amabile, T. M.

1996 Creativity in context: Update to the social psychology of creativity. Boulder, CO:

Westview Press.

Austin, J. T., and J. B. Vancouver

1996 "Goal constructs in psychology: Structure, process, and content." Psychological Bulletin, 120: 338 .

Badaracco, J. L., and J. Useem

1993 "Analyst's dilemma (A) \& (B) TN, The." Harvard Business School Case, 394.

Baer, J.

1994 "Divergent thinking is not a general trait: A multidomain training experiment." Creativity Research Journal, 7: 35-46.

Baron, J., M. H. Bazerman, and K. Shonk

2006 "Enlarging the societal pie through wise legislation a psychological perspective."

Perspectives on Psychological Science, 1: 123-132.

Bazerman, M. H., J. R. Curhan, D. A. Moore, and K. L. Valley

2000 "Negotiation." Annual Review of Psychology, 51: 279-314.

Bazerman, M. H., and F. Gino

2012 "Behavioral ethics: Toward a deeper understanding of moral judgment and dishonesty."

Annual Review of Law and Social Science, 8: 85-104.

Beaussart, M. L., C. J. Andrews, and J. C. Kaufman

2013 "Creative liars: The relationship between creativity and integrity." Thinking Skills and Creativity, 9: 129-134.

Bennis, W. M., D. L. Medin, and D. M. Bartels

2010 "The costs and benefits of calculation and moral rules." Perspectives on Psychological

Science, 5: 187-202.

Brandenburger, A., and B. J. Nalebuff

1996 Co-opetition. New York, NY: Doubleday.

Brief, A. P., R. T. Buttram, and J. M. Dukerich

2001 "Collective corruption in the corporate world: Toward a process model." In M. E. Turner (ed.), Groups at work: Theory and research: 471-499. Mahwah, NJ: Lawrence Erlbaum Associates.

Buhrmester, M., T. Kwang, and S. D. Gosling

2011 "Amazon's Mechanical Turk." Perspectives on Psychological Science, 6: 3-5.

Carnevale, P. J. D., and T. M. Probst 
1998 "Social values and social conflict in creative problem solving and categorization." Journal of Personality and Social Psychology, 74: 1300-1309.

Caruso, E. M., and F. Gino

2010 "Blind ethics: Closing one's eyes polarizes moral judgments and discourages dishonest behavior." Cognition, 118: 280-285.

Chugh, D., and M. H. Bazerman

2007 "Bounded awareness: What you fail to see can hurt you." Mind and Society, 6: 1-18.

Csikszentmihalyi, M., and K. Sawyer

1995 "Creative insight: The social dimension of a solitary moment." In J. M. Sternberg, and J.

E. Davidson (eds.), The nature of insight: 329-363. Cambridge, MA: MIT Press.

Darley, J. M.

1996 "How organizations socialize individuals into evil-doing." In D. M. Messick, and A. E. Tenbrunsel (eds.), Codes of conduct: Behavioral research into business ethics: 13-43. New York, NY: Russell Sage Foundation.

De Dreu, C. K. W.

2003 "Time pressure and closing of the mind in negotiation." Organizational Behavior and Human Decision Processes, 91: 280-295.

De Dreu, C. K. W., M. Giacomantonio, S. Shalvi, and D. Sligte

2009 "Getting stuck or stepping back: Effects of obstacles and construal level in the negotiation of creative solutions." Journal of Experimental Social Psychology, 45: 542-548.

Demoulin, S., and C. P. Teixeira

2010 "Social categorization in interpersonal negotiation: How social structural factors shape negotiations." Group Processes \& Intergroup Relations, 13: 765-777.

Ditto, P. H., D. A. Pizarro, and D. Tannenbaum

2009 "Motivated moral reasoning." In H. R. Brian (ed.), Psychology of Learning and

Motivation: 307-338. San Diego, CA: Academic Press.

Duncker, K., and L. S. Lees

1945 "On problem-solving." Psychological Monographs, 58: i-113.

Fisher, R., W. L. Ury, and B. Patton

2011 Getting to yes: Negotiating agreement without giving in. London, England: Penguin.

Freeman, R. E.

2010 Strategic management: A stakeholder approach. New York, NY: Cambridge University Press.

Gebert, D., S. Boerner, and E. Kearney

2010 "Fostering team innovation: Why is it important to combine opposing action strategies?" Organization Science, 21: 593-608. 
Gilligan, C.

1982 In a different voice. Cambridge, MA: Harvard University Press.

Gino, F., and D. Ariely

2012 "The dark side of creativity: Original thinkers can be more dishonest." Journal of

Personality and Social Psychology, 102: 445-459.

Gino, F., and J. D. Margolis

2011 "Bringing ethics into focus: How regulatory focus and risk preferences influence

(un)ethical behavior." Organizational Behavior and Human Decision Processes, 115: 145-156.

Greenberg, J.

1993 "Stealing in the name of justice: Informational and interpersonal moderators of theft reactions to underpayment inequity." Organizational Behavior and Human Decision Processes, 54: 81-103.

Greene, J. D., S. A. Morelli, K. Lowenberg, L. E. Nystrom, and J. D. Cohen 2008 "Cognitive load selectively interferes with utilitarian moral judgment." Cognition, 107: 1144-1154.

Greene, J. D., L. E. Nystrom, A. D. Engell, J. M. Darley, and J. D. Cohen 2004 "The neural bases of cognitive conflict and control in moral judgment." Neuron, 44: 389400.

Greene, J. D., R. B. Sommerville, L. E. Nystrom, J. M. Darley, and J. D. Cohen 2001 "An fMRI Investigation of Emotional Engagement in Moral Judgment." Science, 293: 2105-2108.

Guilford, J. P. 1968 Intelligence, creativity, and their educational implications. San Diego, CA: Robert R. Knapp.

1982 "Cognitive psychology's ambiguities: Some suggested remedies." Psychological Review, 89: 48.

Gunia, B. C., L. Wang, L. Huang, J. Wang, and J. K. Murnighan

2012 "Contemplation and conversation: Subtle influences on moral decision making." Academy of Management Journal, 55: 13-33.

Haidt, J. 2001 "The emotional dog and its rational tail: A social intuitionist approach to moral judgment." Psychological Review, 108: 814-834.

Harinck, F., and C. K. W. De Dreu

2008 "Take a break! or not? The impact of mindsets during breaks on negotiation processes and outcomes." Journal of Experimental Social Psychology, 44: 397-404.

Isen, A. M., K. A. Daubman, and G. P. Nowicki 
1987 "Positive affect facilitates creative problem solving." Journal of Personality and Social Psychology, 52: 1122-1131.

Jones, T. M.

1991 "Ethical decision making by individuals in organizations: An issue-contingent model." Academy of Management Review, 16: 366-395.

Kant, I.

1998 Critique of pure reason. Cambridge, UK: Cambridge University Press.

Kohlberg, L.

1971 "Stages of moral development." Moral education: 23-92.

Kurtzberg, T. R.

1998 "Creative thinking, cognitive aptitude, and integrative joint gain: A study of negotiator creativity." Creativity Research Journal, 11: 283-293.

Langer, E. J., and A. I. Piper

1987 "The prevention of mindlessness." Journal of Personality and Social Psychology, 53: 280-287.

Larrick, R. P.

2009 "Broaden the decision frame to make effective decisions." In E. A. Locke (ed.), Handbook of principles of organizational behavior: 461-480. Malden, MA: John Wiley \& Sons.

Lewis, M. W.

2000 "Exploring paradox: Toward a more comprehensive guide." Academy of Management Review, 25: 760-776.

Luchins, A. S.

1942 "Mechanization in problem solving: The effect of Einstellung." Psychological Monographs, 54: i-95.

Lüscher, L. S., and M. W. Lewis

2008 "Organizational change and managerial sensemaking: Working through paradox." Academy of Management Journal, 51: 221-240.

MacKinnon, D. P., A. J. Fairchild, and M. S. Fritz 2007 "Mediation analysis." Annual Review of Psychology: 593-614. Palo Alto, CA: Annual Reviews.

Malhotra, D., and M. Bazerman 2007 Negotiation genius: How to overcome obstacles and achieve brilliant results at the bargaining table and beyond. New York, NY: Random House.

McCrae, R. R.

1987 "Creativity, divergent thinking, and openness to experience." Journal of Personality and Social Psychology, 52: 1258-1265. 
Mead, N. L., R. F. Baumeister, F. Gino, M. E. Schweitzer, and D. Ariely 2009 "Too tired to tell the truth: Self-control resource depletion and dishonesty." Journal of Experimental Social Psychology, 45: 594-597.

Mednick, S.

1962 "The associative basis of the creative process." Psychological Review, 69: 220-232.

Miron-Spektor, E., F. Gino, and L. Argote

2011 "Paradoxical frames and creative sparks: Enhancing individual creativity through conflict and integration." Organizational Behavior and Human Decision Processes, 116: 229-240.

Monin, B., D. A. Pizarro, and J. S. Beer

2007 "Deciding versus reacting: Conceptions of moral judgment and the reason-affect debate." Review of General Psychology, 11: 99-111.

Moore, C., J. R. Detert, L. K. Trevino, V. L. Baker, and D. M. Mayer

2012 "Why employees do bad things: Moral disengagement and unethical organizational behavior." Personnel Psychology, 65: 1-48.

Moore, C., and F. Gino

2013 "Ethically adrift: How others pull our moral compass from true North, and how we can fix it." Research in Organizational Behavior, 33: 53-77.

Moore, C., and A. E. Tenbrunsel

2014 "Just think about it? Cognitive complexity and moral choice." Organizational Behavior and Human Decision Processes, 123: 138-149.

Paine, L.

2002 Value shift: Why companies must merge social and financial imperatives to achieve superior performance: McGraw Hill Professional.

Paine, L. S.

1997 "Merck Sharp \& Dohme Argentina, Inc. (A)." Harvard Business School Case, 398.

Palmer, D.

2012 Normal organizational wrongdoing: A critical analysis of theories of misconduct in and by organizations. New York, NY: Oxford University Press.

Pfarrer, M. D., K. A. Decelles, K. G. Smith, and M. S. Taylor 2008 "After the fall: Reintegrating the corrupt organization." Academy of Management Review, 33: 730-749.

Pizarro, D. A., and P. Bloom

2003 "The intelligence of the moral intuitions: A comment on Haidt (2001)." Psychological Review, 110: 193-196.

Rest, J. R., M. J. Bebeau, D. Narvez, and S. J. Thoma 
1999 Postconventional moral thinking: A neo-Kohlbergian approach. Mahwah, NJ: Lawrence Erlbaum.

Reynolds, S. J., C. T. Dang, K. C. Yam, and K. Leavitt

2014 "The role of moral knowledge in everyday immorality: What does it matter if I know what is right?" Organizational Behavior and Human Decision Processes, 123: 124-137.

Rowe, G., J. B. Hirsh, and A. K. Anderson

2007 "Positive affect increases the breadth of attentional selection." Proceedings of the National Academy of Sciences of the United States of America, 104: 383-388.

Runco, M. A.

1991 Divergent thinking. Norwood, NJ: Ablex Publishing.

Schilling, M. A.

2005 "A 'small-world' network model of cognitive insight." Creativity Research Journal, 17: $131-154$.

Schweitzer, M. E., L. Ordóñez, and B. Douma 2004 "Goal setting as a motivator of unethical behavior." Academy of Management Journal, 47: 422-432.

Seifert, C. M., D. E. Meyer, N. Davidson, A. L. Patalano, and I. Yaniv

1994 "Demystification of cognitive insight: Opportunistic assimilation and the prepared-mind hypothesis." In J. M. Sternberg, and J. E. Davidson (eds.), The nature of insight: 65-124. Cambridge, MA: MIT Press.

Shalvi, S., O. Eldar, and Y. Bereby-Meyer

2012 "Honesty requires time (and lack of justifications)." Psychological Science, 23: 12641270.

Shu, L. L., F. Gino, and M. H. Bazerman

2011 "Dishonest deed, clear conscience: When cheating leads to moral disengagement and motivated forgetting." Personality and Social Psychology Bulletin, 37: 330-349.

Shu, L. L., N. Mazar, F. Gino, D. Ariely, and M. H. Bazerman

2012 "Signing at the beginning makes ethics salient and decreases dishonest self-reports in comparison to signing at the end." Proceedings of the National Academy of Sciences, 109: 15197-15200.

Silvia, P. J., B. P. Winterstein, J. T. Willse, C. M. Barona, J. T. Cram, K. I. Hess, J. L. Martinez, and C. A. Richard

2008 "Assessing creativity with divergent thinking tasks: Exploring the reliability and validity of new subjective scoring methods." Psychology of Aesthetics, Creativity, and the Arts, 2: 68-85.

Smith, S. M.

1995 "Getting into and out of mental ruts: A theory of fixation, incubation, and insight." In R. J. S. J. E. Davidson (ed.), The nature of insight: 229-251. Cambridge, MA: MIT Press. 
Smith, W. K., and M. L. Tushman

2005 "Managing strategic contradictions: A top management model for managing innovation streams." Organization Science, 16: 522-536.

Sternberg, R. J.

1988 "A three-facet model of creativity." In R. J. Sternberg (ed.), The nature of creativity: Contemporary psychological perspectives. New York, NY: Cambridge University Press.

Sternberg, R. J., and J. E. Davidson

1995 The nature of insight. Cambridge, MA: MIT Press.

Sternberg, R. J., and T. I. Lubart

1999 "The concept of creativity: Prospects and paradigms." In J. M. Sternberg (ed.), Handbook of creativity: 3-15. Cambridge, UK: Cambridge University Press.

Tenbrunsel, A. E.

1998 "Misrepresentation and expectations of misrepresentation in an ethical dilemma: The role of incentives and temptation." Academy of Management Journal, 41: 330-339.

Tenbrunsel, A. E., K. A. Diekmann, K. A. Wade-Benzoni, and M. H. Bazerman 2010 "The ethical mirage: A temporal explanation as to why we are not as ethical as we think we are." Research in Organizational Behavior, 30: 153-173.

Thomson, J. J.

1986 Rights, restitution, and risk: Essays in moral theory. Cambridge, MA: Harvard University Press.

Tjosvold, D.

1998 "Cooperative and competitive goal approach to conflict: Accomplishments and challenges." Applied Psychology: An International Review, 47: 285-313.

Toffler, B. L.

1986 Tough choices: Managers talk ethics. New York, NY: Wiley.

Trevino, L. K.

1986 "Ethical decision making in organizations: A person-situation interactionist model." Academy of Management Review, 11: 601-617.

Uhlmann, E. L., D. A. Pizarro, D. Tannenbaum, and P. H. Ditto

2009 "The motivated use of moral principles." Judgment and Decision Making, 4: 479-491.

Vaughan, D.

1999 "The dark side of organizations: Mistake, misconduct, and disaster." Annual Review of Sociology, 25: 271-305.

Victor, B., and J. B. Cullen

1988 "The organizational bases of ethical work climates." Administrative Science Quarterly, 33: 101-125. 
Wang, L.

2011 "The Dark Side of Creativity." Ph.D., Northwestern University.

Williams, S. D.

2004 "Personality, attitude, and leader influences on divergent thinking and creativity in organizations." European Journal of Innovation Management, 7: 187-204.

Woodman, R. W., J. E. Sawyer, and R. W. Griffin

1993 "Toward a theory of organizational creativity." Academy of Management Review, 18: 293-321.

Zhong, C. B.

2011 "The ethical dangers of deliberative decision making." Administrative Science Quarterly, 56: $1-25$. 


\section{FIGURE}

Figure 1. Conceptual process model of the factors that generate moral insight.

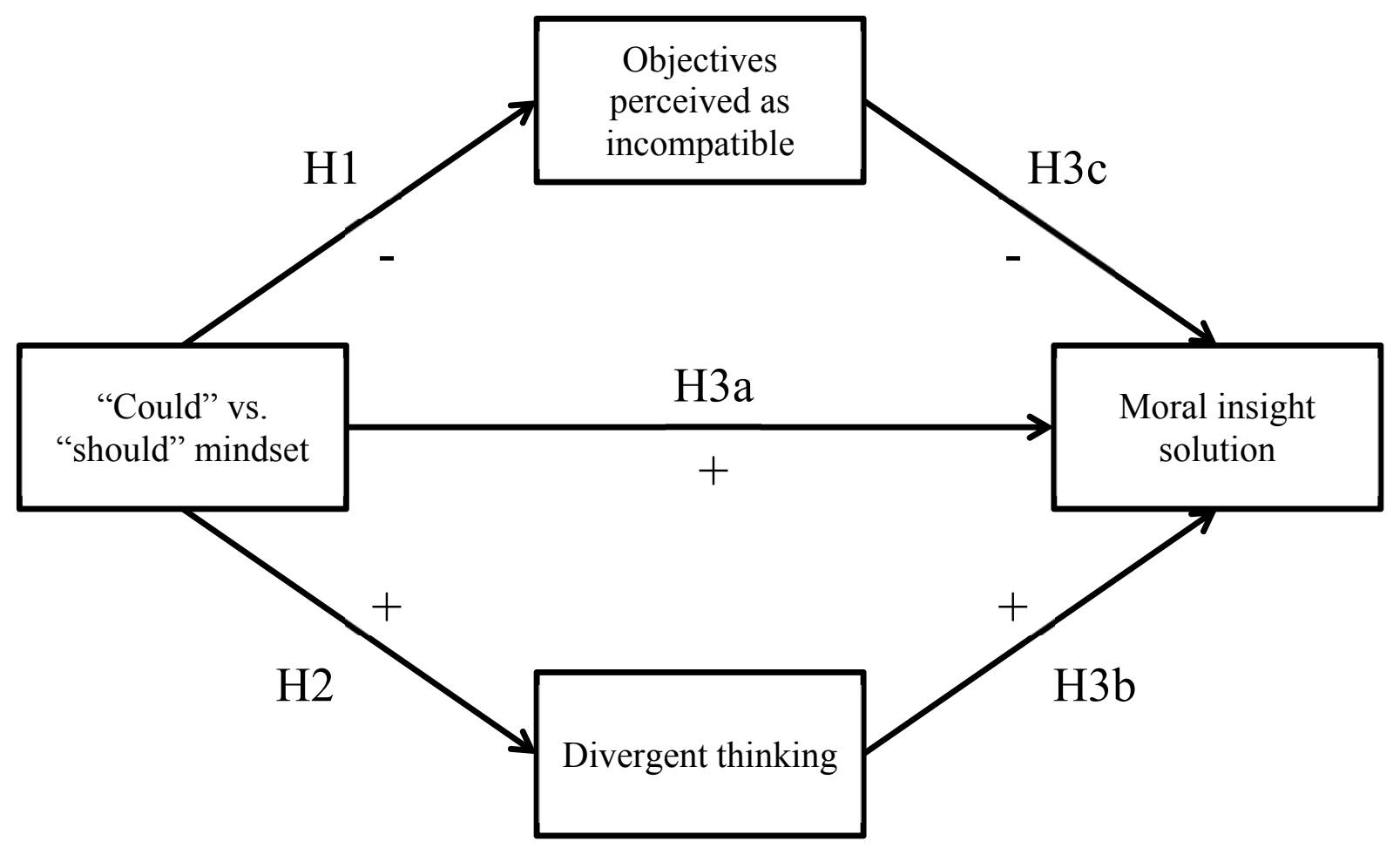




\section{TABLES}

Table 1. Descriptive statistics by condition for the variables measured in Study 1. Standard deviations are reported in parentheses.

\begin{tabular}{ccc}
\hline & "Should" & "Could" \\
\cline { 2 - 3 } Moral Dilemma & $61.54 \%(.36)$ & $8.65 \%(.23)$ \\
Amoral Dilemma & $36.03 \%(.35)$ & $27.94 \%(.28)$ \\
\hline
\end{tabular}

Table 2. Means, standard deviations, and correlations for the variables measured in Study 3.

\begin{tabular}{|c|c|c|c|c|c|c|c|}
\hline Variable & Mean & $\mathrm{SD}$ & 1 & 2 & 3 & 4 & 5 \\
\hline 1. Response contains "could" & 0.56 & 0.84 & & & & & \\
\hline 2. Response contains "should" & 0.21 & 0.55 & -0.02 & & & & \\
\hline $\begin{array}{l}\text { 3. Divergent thinking: self-reported } \\
\text { total number of solutions considered }\end{array}$ & 4.72 & 1.47 & $.52 * * *$ & 0.03 & & & \\
\hline $\begin{array}{l}\text { 4. Divergent thinking: based on } \\
\text { ratings from two independent coders }\end{array}$ & 2.76 & 1.19 & $.41 * * *$ & 0.04 & $.60 * * *$ & & \\
\hline 5. Moral insight solutions & 0.82 & 0.83 & $.23 * * *$ & 0.02 & $.36 * * *$ & $.63 * * *$ & \\
\hline
\end{tabular}

Table 3. Mediation analysis on moral insight solutions formulated (Study 3).

\begin{tabular}{llll}
\hline Variable & $\begin{array}{l}\text { Divergent } \\
\text { thinking }\end{array}$ & $\begin{array}{l}\text { Cumulative moral } \\
\text { insight solutions }\end{array}$ & $\begin{array}{l}\text { Cumulative moral } \\
\text { insight solutions }\end{array}$ \\
& $\mathrm{X} \rightarrow \mathrm{M}$ & $\mathrm{X} \rightarrow \mathrm{Y}$ & $\mathrm{X}, \mathrm{M} \rightarrow \mathrm{Y}$ \\
\hline $\begin{array}{l}\text { "Could" Mindset } \\
\text { Divergent thinking }\end{array}$ & $.21^{* *}$ & $.18^{*}$ & .009 \\
& & $.79^{* * *}$ \\
Adjusted R & .04 & .03 & .62 \\
$95 \%$ bias-corrected CI & & & {$[.10,0.45]$} \\
\hline
\end{tabular}

Note: $C I=$ standardized confidence interval for the indirect effect. The table reports standardized coefficients for each regression.

$* p<.05, * * p<.01, * * * p<.001$ 
Table 4. Solutions discussed in conversations with partner in Study 4. Creativity and quality of solutions are based on ratings of 101 independent coders.

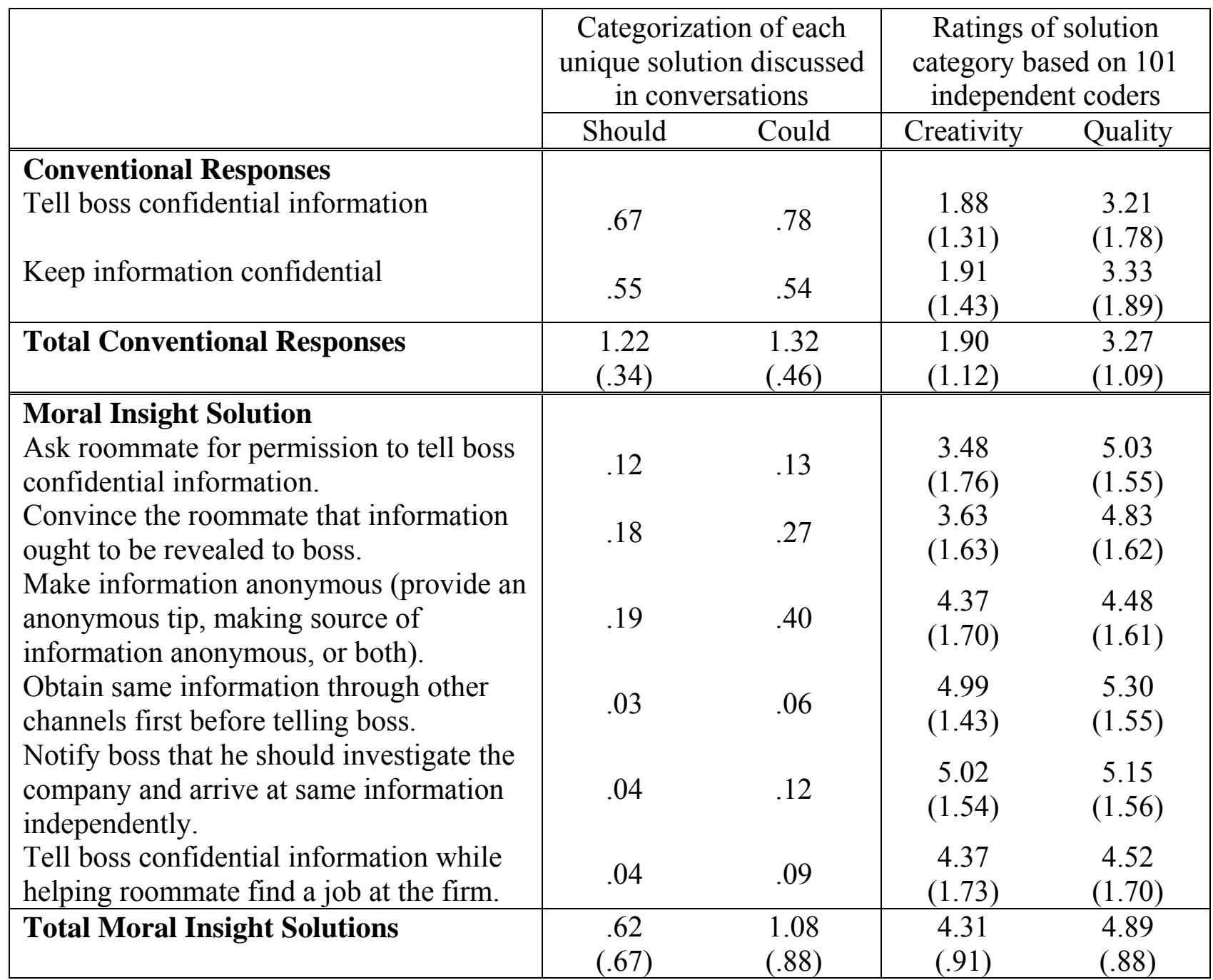


Table 5. Descriptive statistics by condition for responses to ultimate solutions to the question

"What would you do?" in Study 4. Standard deviations are reported in parentheses.

\begin{tabular}{|c|ccc|cc|}
\hline \multirow{2}{*}{ Mindset } & \multicolumn{2}{|c|}{ P's own perception of the ultimate solution } & \multicolumn{2}{c|}{$\begin{array}{c}\text { Two independent rater's coding } \\
\text { of the ultimate solution }\end{array}$} \\
\cline { 2 - 6 } & $\begin{array}{c}\text { Perceived } \\
\text { incompatibility }\end{array}$ & $\begin{array}{c}\text { Perceived } \\
\text { creativity }\end{array}$ & $\begin{array}{c}\text { Met multiple } \\
\text { objectives }\end{array}$ & $\begin{array}{c}\text { Moral insight } \\
\text { solution }\end{array}$ & $\begin{array}{c}\text { Thoughtfulness } \\
\text { of solution }\end{array}$ \\
\hline Should & $1.76(.88)$ & $2.84(1.74)$ & $3.60(1.94)$ & $35.3 \%$ & $3.33(1.51)$ \\
Could & $1.44(.86)$ & $3.61(1.78)$ & $4.35(2.01)$ & $60.2 \%$ & $3.90(1.32)$ \\
\hline
\end{tabular}

Table 6. Mediation analysis on propensity to generate moral insight (Study 4).

\begin{tabular}{llll}
\hline Variable & $\begin{array}{l}\text { Perceived } \\
\text { incompatibility }\end{array}$ & $\begin{array}{l}\text { Likelihood of } \\
\text { formulating moral } \\
\text { insight solution }\end{array}$ & $\begin{array}{l}\text { Likelihood of } \\
\text { formulating moral } \\
\text { insight solution }\end{array}$ \\
& $\mathrm{X} \rightarrow \mathrm{M}$ & $\mathrm{X} \rightarrow \mathrm{Y}$ & $\mathrm{X}, \mathrm{M} \rightarrow \mathrm{Y}$ \\
\hline $\begin{array}{l}\text { "Could" Mindset } \\
\text { Incompatibility }\end{array}$ & $-.31^{*}$ & $.25^{* * *}$ & $.20^{* *}$ \\
Adjusted $\mathrm{R}^{2}$ & & & $-.16^{* * *}$ \\
95\% bias-corrected CI & .03 & .07 & .15 \\
\hline
\end{tabular}

Note: $C I=$ unstandardized confidence interval for the indirect effect. The table reports unstandardized coefficients for each regression.

${ }^{*} p<.05, * * p<.01, * * * p<.001$ 


\section{APPENDIX A}

As you consider your response to each situation, please fill in the blank with the word that best captures how you are thinking about the problem.

What I do?

\section{Moral Dilemma 1}

Adapted from the "Heinz dilemma" (Kohlberg, 1971).

Imagine that your spouse is near death from a rare kind of cancer. There was one drug that the doctors thought might save your spouse's life. It was a form of radium that a scientist in the same town had recently discovered. The drug was expensive to make, but the scientist, who sold the drug through a drug store he owned, was charging ten times what the drug cost him to make. He paid \$200 for the radium and charged \$2,000 for a small dose of the drug.

You went to everyone you knew to borrow the money, but you could only get together about $\$ 1,000$, which is half of what the drug cost. You told the scientist that your spouse was dying and asked him to sell it cheaper or let him pay later. But the scientist said: "No, I discovered the drug and I'm going to make money from it." So you got desperate and considered breaking into the man's store to steal the drug for your spouse.

\section{Moral Dilemma 2}

Adapted from “Merck Sharp \& Dohme Argentina, Inc.” (Paine, 1997).

You are the manager of a multinational pharmaceutical company's unit in Argentina, and you are facing a difficult situation. You took over the company's unit in Argentina with the expectation that you would modernize its practices, infuse the company with a high standard of integrity and fairness, make the culture more professional, and improve performance dramatically. However, the company is still not on target to meet its sales goal for the year.

To make these goals, you have established a new internship program to recruit top caliber talent for possible careers with the company. From a pool of top-notch college students, the company would select 15 for a paid summer internship program.

You enlisted an outside consulting firm to handle the actual recruiting. The consulting company sifted through over 1,200 applicants and after an intense battery of tests only 30 were then selected to participate in a two-week program overseen by the company's senior managers, who would test the 30 candidates' skills in a variety of exercises. The final 15 would be selected at the end of those two weeks.

Just two days before you were set to announce the 15 college students chosen for the highlyselective summer intern program, you received a phone call from a middle manager who informed you that one of the candidates was the son of a high-ranking official in the government's national health care program for government retirees, the single largest health care organization in the country. The student's presence in the company workforce, the manager 
stated, would give the company an excellent opportunity to increase sales well beyond the goal that you had set by ensuring that all its drugs were included in the government health care formulary. Any company would envy you for this unexpected advantage. Of the 30 candidates, however, this particular individual was ranked number 16 on the list, just below the cut. The rankings were based upon the battery of tests and senior managers' evaluations.

When Friday morning arrived, you were unsure how to proceed, but you had to inform the winning interns today.

\section{Amoral Dilemma 1}

You have been working hard on an essay assignment for the last week. The prompt was about how the country setting of novels play a role in these pieces of literature. You meticulously went through the readings centered around how different types of government policies are featured in these stories.

Two days before the deadline, you realized that you mis-interpreted the essay prompt. The question was focused on how the pastoral and farm settings (not the setting of nations) in novels play a role in works of literature.

\section{Amoral Dilemma 2}

You are currently in the Boston airport and have a job interview scheduled in New York in 5 hours. The flight is only 1 hour in duration and your interview is a thirty-minute commute away once you land in New York. You booked this flight since it would give you plenty of time to get to the meeting.

Just as you thought you were about to board the plane, the flight attendant announced that your flight is cancelled due to the plane's engine problems. The next available flight in which you are guaranteed a seat is not for another 4 hours, which would make you late for your interview. 


\section{Moral Dilemma 1}

\section{APPENDIX B}

Adapted from the "Heinz dilemma" (Kohlberg, 1971).

Imagine that your spouse is near death from a rare kind of cancer. There was one drug that the doctors thought might save your spouse's life. It was a form of radium that a scientist in the same town had recently discovered. The drug was expensive to make, but the scientist, who sold the drug through a drug store he owned, was charging ten times what the drug cost him to make. He paid \$200 for the radium and charged \$2,000 for a small dose of the drug.

You went to everyone you knew to borrow the money, but you could only get together about $\$ 1,000$, which is half of what the drug cost. You told the scientist that your spouse was dying and asked him to sell it cheaper or let him pay later. But the scientist said: "No, I discovered the drug and I'm going to make money from it." So you got desperate and considered breaking into the man's store to steal the drug for your spouse.

What could/should you do?

To what extent do you think 1) saving your spouse's life and 2) not breaking the law (not stealing the drug) are compatible/incompatible?

\section{Moral Dilemma 2}

Adapted from “Merck Sharp \& Dohme Argentina, Inc." (Paine, 1997).

You are the manager of a multinational pharmaceutical company's unit in Argentina, and you are facing a difficult situation. You took over the company's unit in Argentina with the expectation that you would modernize its practices, infuse the company with a high standard of integrity and fairness, make the culture more professional, and improve performance dramatically. However, the company is still not on target to meet its sales goal for the year.

To make these goals, you have established a new internship program to recruit top caliber talent for possible careers with the company. From a pool of top-notch college students, the company would select 15 for a paid summer internship program.

You enlisted an outside consulting firm to handle the actual recruiting. The consulting company sifted through over 1,200 applicants and after an intense battery of tests only 30 were then selected to participate in a two-week program overseen by the company's senior managers, who would test the 30 candidates' skills in a variety of exercises. The final 15 would be selected at the end of those two weeks.

Just two days before you were set to announce the 15 college students chosen for the highlyselective summer intern program, you received a phone call from a middle manager who informed you that one of the candidates was the son of a high-ranking official in the government's national health care program for government retirees, the single largest health care organization in the country. The student's presence in the company workforce, the manager stated, would give the company an excellent opportunity to increase sales well beyond the goal 
that you had set by ensuring that all its drugs were included in the government health care formulary. Any company would envy you for this unexpected advantage. Of the 30 candidates, however, this particular individual was ranked number 16 on the list, just below the cut. The rankings were based upon the battery of tests and senior managers' evaluations.

When Friday morning arrived, you were unsure how to proceed, but you had to inform the winning interns today.

What could/should you do?

To what extent do you think 1) giving your company a financial advantage by hiring candidate 16 and 2) being fair to the other candidates are compatible/incompatible?

\section{Moral Dilemma 3}

Adapted from an experience of a former MBA student

Imagine that you work in the financial office of Climatex, a large company that manufactures heating ventilation and air conditioning (HVAC) equipment. The CEO has been examining potential acquisitions in "new energy," such as wind, solar, and geothermal. The board of directors has informed the $\mathrm{CEO}$ that any acquisition must promise at least a $6 \%$ return and, preferably, a return between $7 \%$ and $9 \%$. In order to be approved, every potential acquisition needs to be presented with financial analysis that is reviewed by the board.

A friend of the CEO owns a solar-panel company, in which the CEO invested. The CEO asked you to conduct a financial analysis of the friend's company since the CEO wanted to propose that Climatex acquire the friend's company. The CEO asked that you prepare a report for the board. In the CEO's meeting with you, the CEO concluded, "This is a great opportunity for our company. Let's find a way to recommend this as positively as possible to the board."

You were excited by the project - a high profile assignment and a chance to present to the board of directors. You conducted financial analyses in the two most common and accepted methods for doing so, and one method revealed a return of $4.5 \%$ and the other revealed a return of 5.35\%. Even with optimistic assumptions, the return fell underneath the $6 \%$ return standard set by the board. Before meeting with the CEO, you reviewed your work with a colleague you respected, and they came to the same results.

When you met with the CEO to share your analyses, the CEO asked you if the returns would look better if you changed some of the underlying assumptions in the analyses. The CEO finished the conversation by saying, "We just need a glowing recommendation to get the approval we need from the board on this one. This is your moment to shine and show your potential. Let's see you deliver what we need."

You felt conflicted. You would need to write a report containing three components: a description of the solar-panel company and its prospects, a quantitative analysis of estimated financial return, and a concluding recommendation to be presented in front of the board of directors. You did not want to damage your career going against the CEO, but at the same time, 
you wanted to maintain your integrity and make a recommendation that would not squander the company's resources.

What could/should you do?

To what extent do you think 1) maintaining your integrity and 2) not damaging your career are compatible/incompatible?

\section{Moral Dilemma 4}

Adapted from the "Analyst's Dilemma" (Badaracco and Useem, 1993).

Imagine that you are a rising star at a medium-sized investment bank (B\&B), and you are currently facing a decision to choose between loyalty to your roommate or to your company and boss. To understand this predicament, it is important to understand that there exists a cult mentality at B\&B in that those who stay at the company accept that loyalty to the organization goes before one's health, family, and friends.

The situation started when you were working on a project that involved orchestrating a leveraged buyout for Suntech, one of B\&B's clients. In addition to providing short-term financing, B\&B put together the syndicate of banks financing the deal and purchased the majority of Suntech's assets, to be held for a long-term basis. Universal was another bank on the team that was involved with the structuring of the deal, underwriting the loan for the senior debt. It turns out that your roommate, Sandy was one of the people on Universal's team working on the project.

One day after work, you came home to find your roommate Sandy in tears. Sandy basically pleaded for you to keep your conversation confidential, and you agreed, thinking this was a personal issue. It turned out that Universal was dissolving its capital finance group, meaning that not only was Sandy out of a job, but now the deal with B\&B was in serious jeopardy. If you do not tell your boss at $\mathrm{B} \& \mathrm{~B}$ about this news right away, then the public might hear of the news first, scaring away potential investors and putting both $\mathrm{B} \& \mathrm{~B}$ and the client at risk. At the same time, you made a promise that Sandy would not tell anyone about the situation since this information is confidential.

What could/should you do?

To what extent do you think 1) maintaining the confidentiality agreement with your roommate and 2 ) informing your boss about the news are compatible/incompatible? 